University of Nebraska - Lincoln

DigitalCommons@University of Nebraska - Lincoln

\title{
Evaluation of propane combustion traps for the collection of Phlebotomus papatasi (Scopoli) in southern Israel
}

\author{
Daniel Kline \\ United States Department of Agriculture-ARS-Center for Medical, Agricultural \\ Gunter Miller \\ Kuvin Centre for the Study of Infectious and Tropical Diseases \\ Jerome Hogsette \\ United States Department of Agriculture-ARS-Center for Medical, Agricultural
}

Follow this and additional works at: https://digitalcommons.unl.edu/usdaarsfacpub

Part of the Agricultural Science Commons

Kline, Daniel; Miller, Gunter; and Hogsette, Jerome, "Evaluation of propane combustion traps for the collection of Phlebotomus papatasi (Scopoli) in southern Israel" (2011). Publications from USDA-ARS / UNL Faculty. 1021.

https://digitalcommons.unl.edu/usdaarsfacpub/1021

This Article is brought to you for free and open access by the U.S. Department of Agriculture: Agricultural Research Service, Lincoln, Nebraska at DigitalCommons@University of Nebraska - Lincoln. It has been accepted for inclusion in Publications from USDA-ARS / UNL Faculty by an authorized administrator of DigitalCommons@University of Nebraska - Lincoln. 


\title{
Evaluation of propane combustion traps for the collection of Phlebotomus papatasi (Scopoli) in southern Israel
}

\author{
Daniel L. Kline ${ }^{1}$, Günter C. Müller², and Jerome A. Hogsette ${ }^{1}$ \\ ${ }^{1}$ United States Department of Agriculture-ARS-Center for Medical, Agricultural, and Veterinary Entomology, \\ Gainesville, FL, U.S.A. \\ ${ }^{2}$ Department of Microbiology and Molecular Genetics, IMRIC, Kuvin Centre for the Study of Infectious and Tropical Diseases, \\ Faculty of Medicine, Hebrew University, Jerusalem, Israel, 91120
}

\begin{abstract}
In this study, we evaluated the efficacy of eleven commercial models of propane combustion traps for catching male and female Phlebotomus papatasi. The traps differed in physical appearance, amount of carbon dioxide produced and released, type and location of capturing device, and the method by which the trap suction fans were powered. The traps tested were the Mosquito Magnet ${ }^{\mathrm{m}}(\mathrm{MM})$-Pro, MM-Liberty, MM-Liberty Plus, MM-Defender, SkeeterVac ${ }^{\circ}(\mathrm{SV})-35, \mathrm{SV}-27$, Mosquito Deleto"'(MD)-2200, MD-2500, MT150-Power Trap, and two models of The Guardian Mosquito Traps (MK-01 and MK-12). All trap models except the SV-35, the SV-27, the MD-2500, and the MK-12 attracted significantly more females than males. The SV-35 was the most efficient trap, catching significantly more females than all the other models. The MD2200 and MK-12 models were the least effective in catching either female or male sand flies. These data indicate that several models of propane combustion traps might be suitable substitutes for either $\mathrm{CO}_{2}$-baited or unbaited light traps for adult sand fly surveillance tools. One advantageous feature is the traps' ability to remain operational $24 / 7$ for ca. 20 days on a single tank of propane. Additionally, the models that produce their own electricity to power the trap's fans have an important logistical advantage in field operations over light traps, which require daily battery exchange and charging. Journal of Vector Ecology 36 (Supplement 1): S166-S171. 2011.
\end{abstract}

Keyword Index: Sand flies, thermoelectric, surveillance, light, carbon dioxide, CDC trap.

\section{INTRODUCTION}

Phlebotomine sand flies have a wide distribution, mainly in the tropics and subtropics (Adler and Theodor 1957). They are proven vectors of leishmaniasis, bartonellosis (Birtles 2001) and numerous viruses including phleboviruses, flaviviruses, orbiviruses and vesiculoviruses (Comer and Tesh 1991, Ashford 2001). Two Leishmania species cause leishmaniasis in the Old World, Leishmania major Yakimimoff and Schokhornin and L. tropica Wright. In Israel, the epidemiology of cutaneous leishmaniasis, due to L. major has been investigated and clearly defined as zoonotic, with Psammomys obesus Cretzschmar and Meriones crassus Sundevall as the main rodent reservoir hosts and Phlebotomus papatasi Scopoli as the vector (Schein et al. 1982, 1984, Wasserburg et al. 2003b, Jaffe et al. 2004) Cutaneous leishmaniasis is endemic in large parts of Israel and the West Bank (Wasserburg et al., 2003a, 2003b, Al-Jawabreh et al. 2004, Jaffe et al. 2004). Phlebotomus papatasi is an important vector of the disease in the Jordan Valley and southern Israel where large sand fly populations are found in the burrows of the rodent reservoirs (Schlein et al. 1982, 1984, Jainini et al. 1995).

CDC light traps and sticky papers have been the standard sampling methods for monitoring adult populations of sand flies (Killick-Kendrick 1987, Alexander 2000, Faiman et al. 2009). Recent developments in mosquito monitoring/control technology in the U.S. has resulted in the production of various models of commercial traps for the consumer market, which utilize the combustion of propane to produce carbon dioxide $\left(\mathrm{CO}_{2}\right)$ and other attractants. While these traps were designed for the collection and control of mosquitoes, they have also been used to collect large numbers of Culicoides spp. (Ceratopogonidae) biting midges (Cilek and Hallmon 2005, Cilek et al. 2003) in the U.S.; some Lutzomyia have been collaterally collected. To our knowledge, no one has conducted any study to compare the efficacy of the various models of these commercially available propane powered traps for the capture of any species of phlebotomine sand fly. Therefore, the major objective of this study was to compare the efficacy of eleven models of propane powered traps to capture P. papatasi.

\section{MATERIALS AND METHODS}

\section{Study site}

The study was conducted October 11-22, 2005, in a zoonotic focus of L. major in Neot Hakikar oasis in the southern Jordan Valley in Israel. The oasis is known for its rich mosquito fauna (Margalit et al. 1973), however the only sand fly species recovered has been $P$. papatasi (Schlein et al. 1984, Muller and Schlein 2004). The whole endemic region is classified as an extreme desert and belongs to the Sahara-Arabian phyto-geographical zone (Danin 1988). In this zone, the rainy season is very short and the summer is extremely dry and hot. The annual rainfall is $50 \mathrm{~mm}$ in the south and $100 \mathrm{~mm}$ in the north (Ashbel 1951). Average daily temperature is $20^{\circ} \mathrm{C}$ from the end of September to 


\section{Report Documentation Page}

Public reporting burden for the collection of information is estimated to average 1 hour per response, including the time for reviewing instructions, searching existing data sources, gathering and maintaining the data needed, and completing and reviewing the collection of information. Send comments regarding this burden estimate or any other aspect of this collection of information, including suggestions for reducing this burden, to Washington Headquarters Services, Directorate for Information Operations and Reports, 1215 Jefferson Davis Highway, Suite 1204, Arlington VA 22202-4302. Respondents should be aware that notwithstanding any other provision of law, no person shall be subject to a penalty for failing to comply with a collection of information if it does not display a currently valid OMB control number.

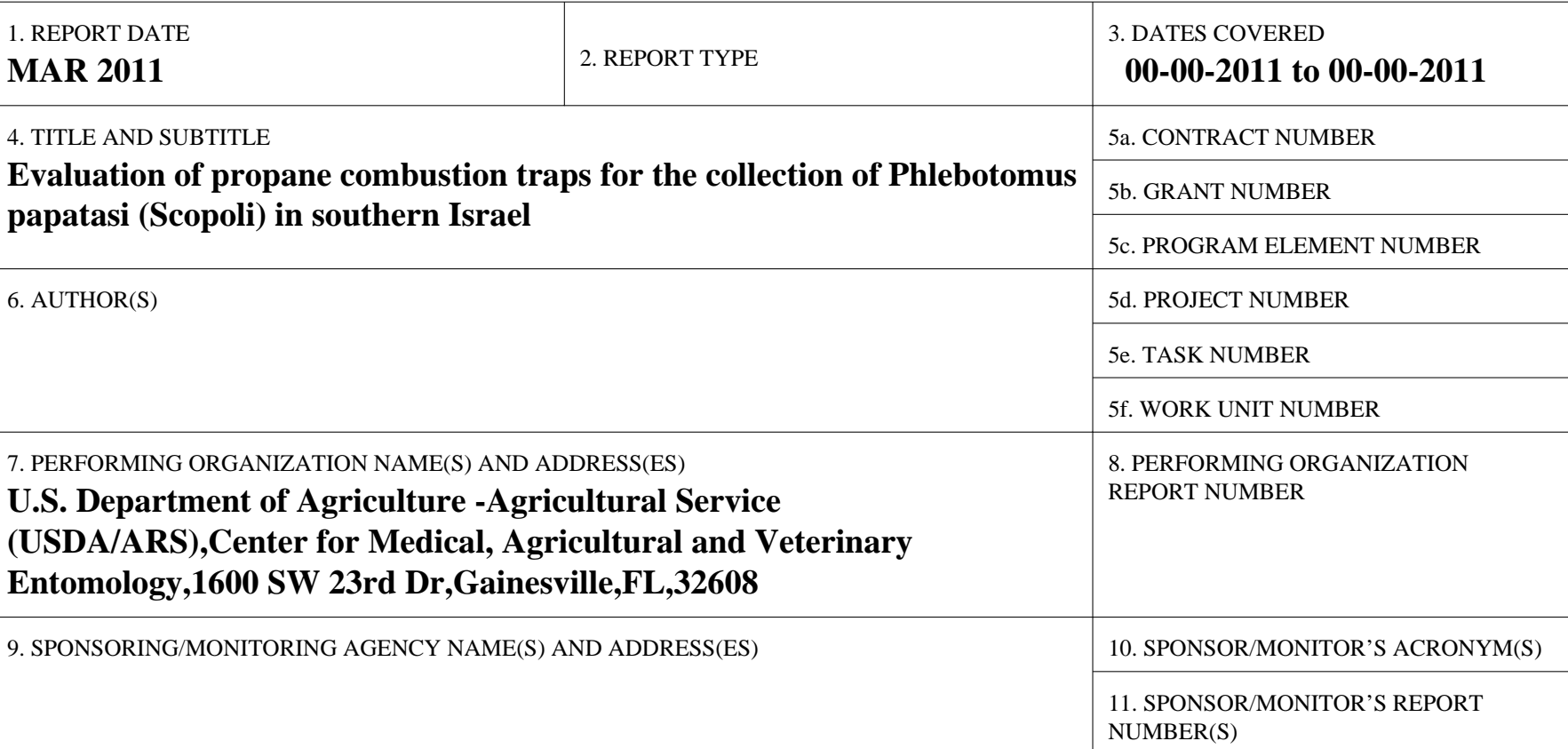

12. DISTRIBUTION/AVAILABILITY STATEMENT

Approved for public release; distribution unlimited

13. SUPPLEMENTARY NOTES

14. ABSTRACT

In this study, we evaluated the efficacy of eleven commercial models of propane combustion traps for catching male and female Phlebotomus papatasi. The traps differed in physical appearance, amount of carbon dioxide produced and released, type and location of capturing device, and the method by which the trap suction fans were powered. The traps tested were the Mosquito Magnet?(MM)-Pro, MM-Liberty, MM-Liberty Plus, MM-Defender, SkeeterVac?(SV)-35, SV-27 Mosquito Deleto?(MD)-2200, MD-2500, MT150-Power Trap, and two models of The Guardian Mosquito Traps (MK-01 and MK-12). All trap models except the SV-35, the SV-27, the MD-2500, and the MK-12 attracted significantly more females than males. The SV-35 was the most efficient trap, catching significantly more females than all the other models. The MD- 2200 and MK-12 models were the least effective in catching either female or male sand flies. These data indicate that several models of propane combustion traps might be suitable substitutes for either CO2-baited or unbaited light traps for adult sand fly surveillance tools. One advantageous feature is the traps? ability to remain operational $24 / 7$ for ca. 20 days on a single tank of propane. Additionally, the models that produce their own electricity to power the trap?s fans have an important logistical advantage in field operations over light traps, which require daily battery exchange and charging. Journal of Vector Ecology 36 (Supplement 1): S166-S171. 2011.

15. SUBJECT TERMS

16. SECURITY CLASSIFICATION OF:

a. REPORT unclassified b. ABSTRACT unclassified c. THIS PAGE unclassified
17. LIMITATION OF ABSTRACT

Same as Report (SAR)
18. NUMBER 19a. NAME OF OF PAGES RESPONSIBLE PERSON 
Standard Form 298 (Rev. 8-98) Prescribed by ANSI Std Z39-18 
early April and $30^{\circ} \mathrm{C}$ from May to August with extreme heat waves of up to $50^{\circ} \mathrm{C}$ in the summer (Orni and Efrat 1980).

Neot Hakikar, the largest oasis on the shore of the Dead Sea, covers an area of about 50 square kilometers. In the oasis there is a small village with irrigated gardens, cultivated fields and green houses. The village is surrounded by natural areas, which include marshland, numerous springs, plains that are flooded in winter by overflow of nearby wadies, which become dried up salt pans in the summer. The vegetation, particularly near the springs, is a rich mixture of Ethiopian and Palearctic flora (Zohary and Orshansky 1949). Within this natural vegetation a date plantation is located. The plantation is surrounded by groves and thickets of trees and bushes like Tamarix nilotica (Ehrenb.) Bge. and T. passerinoides Del. Ex Desv. (Tamaricaceae), Prosopis farcta (Macbride) (Mimosaceae), Nitraria retusa (Forssk.) Asch. (Nitrariaceae) and chenopod bushes like Atriplex halimus (L.), A. leucoclada Boiss., Suaeda asphaltica (Boiss.), S. frutiicosa Forsk. (Chenopodiaceae).

\section{Commercial propane-based combustion traps}

Eleven commercially available trap models were compared. They were similar in that they were all designed to mimic a vertebrate host through the combustion of propane to generate heat, moisture, and $\mathrm{CO}_{2}$ to attract biting insects. The traps differed in physical appearance (e.g. color patterns, shape and height), amount of $\mathrm{CO}_{2}$ produced and point of release, type and location of capturing device, presence/absence of fans, the method (counterflow updraft versus downdraft) used by these fans to vacuum the insects into the collection device, and the power source for the fans (i.e. mains electricity versus thermoelectric generation of electricity by means of propane combustion). The traps were assembled, operated, and maintained according to the manufacturers' instructions, except that no octenol baits were used based on previously reported studies, which showed that octenol had either no effect or a slightly repellent effect on the collection of $P$. papatasi (Beavers et al. 2004). Major trap features are summarized in Table 1.

The trap models tested were: the Mosquito Magnet ${ }^{\mathrm{mm}}$ (MM)-Pro, MM-Liberty, MM-Liberty Plus, and MMDefender (Woodstream, Littiz, PA); Skeeter Vacuum ${ }^{\circledR}$ (SV)27 and SV-35 (Blue Rhino, Winston Salem, NC); Mosquito Deleto $^{\mathrm{Tx}}$ (MD)-2200 and MD-2500 Active System (The Coleman Company, Wichita, KS); MT150-Power Trap (Flowtron, Malden, MA); and The Guardian Mosquito Traps MK-01 and MK-12 (Lentek/Koolatron, Chicago, IL). In addition to using propane combustion to produce the attractants listed above, five trap models (MM-Pro, MMLiberty Plus, SV-27, SV-35 and MD-2500) utilize some type of thermoelectric module to capture some of the heat produced by the combustion process to produce electricity to power the suction fans. These traps are cordless. The MM-Liberty, MM-Defender, MK-01, MK-12 and the MT 150 Power Trap were provided A.C. (mains) current by the generation of electricity by means of gasoline-powered generators. Only one trap, the MD-2200 did not use a suction fan and therefore had no need for electricity; its attractants were distributed by passive diffusion away from the trap. Various trap models used different collection devices. The MD-2200 used all black sticky (glue) panels to capture attracted insects; the SV-27 and SV-35 used a combination of sticky papers (alternating patterns of black and white) and a specially designed suction collection cup to simultaneously capture attracted insects. The rest of the trap models used vacuum created by suction fans to capture attracted insects into either nets (MM-Pro, MMLiberty, MM-Liberty Plus and MD-2500) or specially designed collection devices (MM-Defender, MT-150 Power Trap, MK-01 and MK-12). In addition to the attractants generated by propane combustion, five traps used light as an additional attractant. The SV-27 and SV-35 used several colors of flickering LEDs, the MK-01 and MK-12 used a constantly lit blue LED, and the MT-150 used a constantly lit green LED.

\section{Experimental design}

The study was conducted for 11 consecutive nights along the elevated embankment of a drainage canal, which separated a nature reserve from the cultivated areas. Eleven trapping stations, ca. $50 \mathrm{~m}$ apart, were established in a continuous line parallel to the drainage canal. A 9-kg (20 lb) propane tank was placed at each trapping station.

Each day the traps were rotated clockwise to the next trapping station at 17:00 to reduce positional bias. During the eleven nights of trapping, each trap model was operated at each trapping station for one night. Trap collections were made at 07:00 each day to prevent degradation of the specimens.

\section{Statistical analysis}

Data were first normalized by conversion to square root then subjected to ANOVA (SAS 2003) using the following model statement: Female Male Total $=$ Treatment Position Day Sex, where dependent variables represented numbers of sand flies captured. Treatment was one of the 11 traps, Position was one of the 11 trap locations, and Day was one of the 11 consecutive trapping days of the study. Means were separated with the Ryan-Einot-Gabriel-Welsch Multiple Range Test (REGWQ), and unless otherwise stated, $P<0.05$ (SAS 2003). Although square root values were used for the analyses, actual values are reported in the text, figures and tables.

\section{RESULTS}

Main effects models were significant for all three dependent variables (Female, $F=14.32$, d. $f=30,90, P<0.0001$; Male, $F=16.61$, d.f. $=30,90, \quad P<0.0001$; Total, $F=18.02$, d.f. $=30,90, P<0.0001)$. Means for the total numbers of flies captured ranged from 363.0 to 28.1 (Table 2) and overall, traps captured significantly more females than males.

\section{Females}

Means for females captured ranged from 212.6 to 19.2 (Table 2). The Blue Rhino SV 35 captured significantly more 


\begin{tabular}{|c|c|c|c|c|c|c|c|c|c|c|c|}
\hline 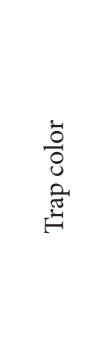 & 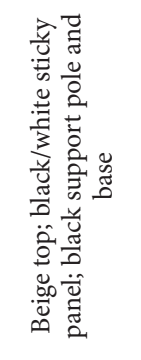 & 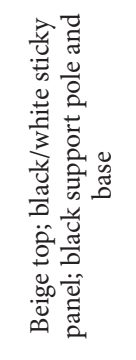 & 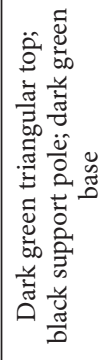 & 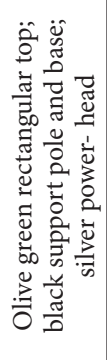 & 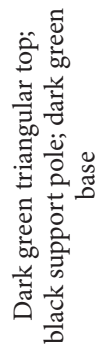 & 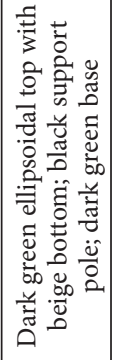 & 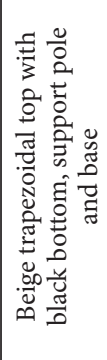 & 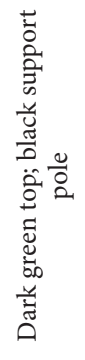 & 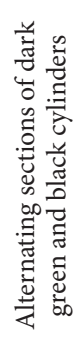 & 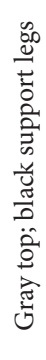 & 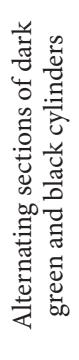 \\
\hline 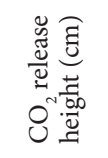 & ڤ̂̀ & ڤે & $\stackrel{\circ}{\circ}$ & $\begin{array}{l}\infty \\
\stackrel{\infty}{i n}\end{array}$ & $\stackrel{\circ}{\stackrel{4}{f}}$ & $\underset{\mathfrak{H}}{\mathfrak{H}}$ & $\stackrel{\circ}{\underset{+}{-}}$ & గֶ & $\hat{\circ}$ & $\begin{array}{l}\text { in } \\
\text { o }\end{array}$ & $\vec{\infty}$ \\
\hline 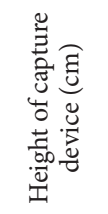 & 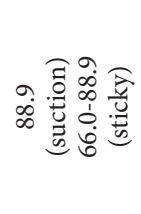 & 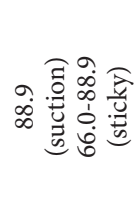 & ڤn & $\begin{array}{l}\infty \\
\stackrel{0}{0} \\
\text { in }\end{array}$ & ڤે & $\begin{array}{l}\circ \\
\text { f }\end{array}$ & $\vec{i}$ & ஷ̊? & 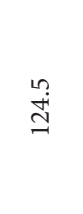 & 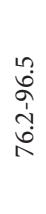 & $\stackrel{m}{n}$ \\
\hline 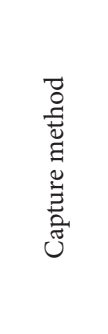 & 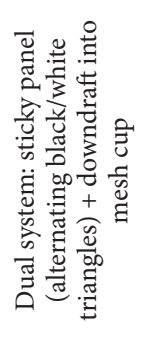 & 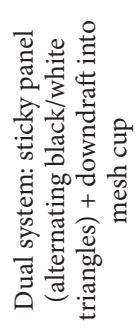 & 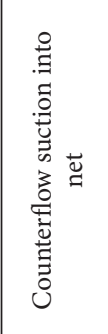 & 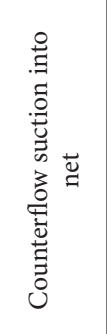 & 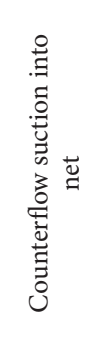 & 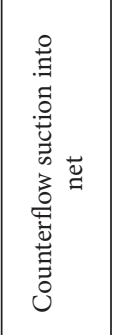 & 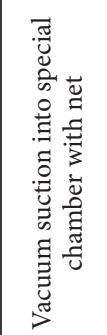 & 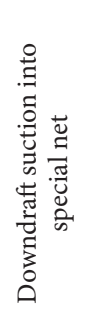 & 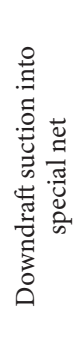 & 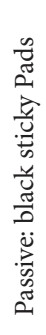 & 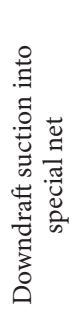 \\
\hline 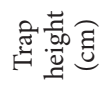 & $\widehat{\widehat{\sigma}}$ & $\hat{\sigma}$ & $\dot{\infty}_{\infty}^{\infty}$ & $\underset{-}{\stackrel{a}{0}}$ & $\begin{array}{l}\infty \\
\infty \\
\infty\end{array}$ & ดे & $\stackrel{\text { Ln }}{\tilde{0}}$ & ָָ & $\begin{array}{l}\vec{i} \\
\stackrel{\sim}{\sim}\end{array}$ & $\hat{\alpha}$ & $\infty_{\infty}^{\infty}$ \\
\hline 总 & 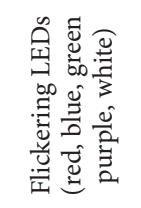 & 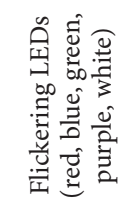 & $\begin{array}{l}\text { Z̆ } \\
\text { z }\end{array}$ & 芩 & $\begin{array}{l}\text { Z̃ } \\
\text { z }\end{array}$ & 苂 & 苂 & 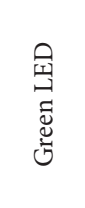 & 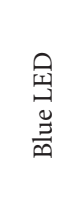 & $\begin{array}{l}\text { Z } \\
\text { ż }\end{array}$ & 空 \\
\hline O & $\begin{array}{l}\infty \\
\infty \\
\text { in }\end{array}$ & 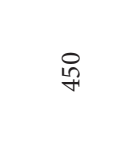 & \& & in & \& & $\underset{i n}{8}$ & \& & $\stackrel{i n}{\wedge}$ & 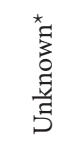 & \&্ల & 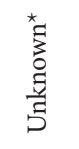 \\
\hline 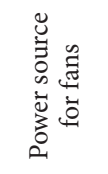 & 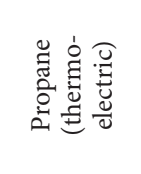 & 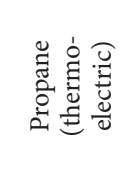 & 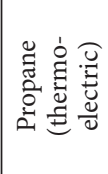 & 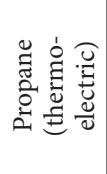 & 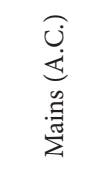 & 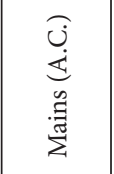 & 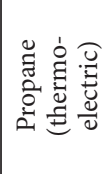 & 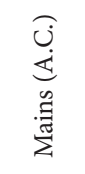 & 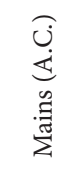 & $\begin{array}{l}\text { : } \\
\text { ż }\end{array}$ & 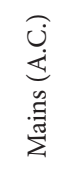 \\
\hline 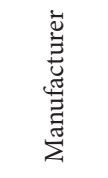 & 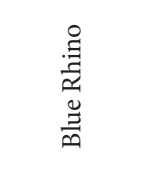 & 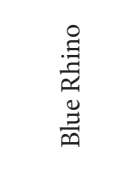 & 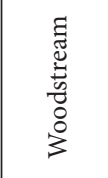 & 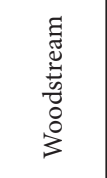 & 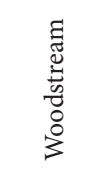 & 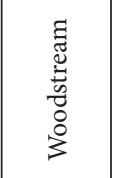 & 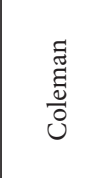 & 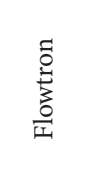 & 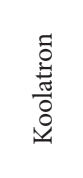 & $\frac{\text { चี }}{\text { हี }}$ & 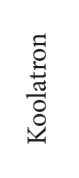 \\
\hline 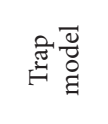 & $\frac{m}{m}$ & $\begin{array}{c}\hat{1} \\
\stackrel{1}{n} \\
\text { is }\end{array}$ & $\sum_{\substack{\mathrm{D} \\
:}}^{+}$ & $\sum_{i=1}^{\infty}$ & 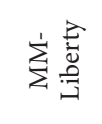 & 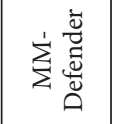 & $\begin{array}{l}8 \\
\stackrel{1}{1} \\
\stackrel{2}{\Sigma}\end{array}$ & 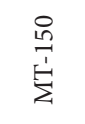 & $\begin{array}{l}\overrightarrow{0} \\
\dot{z}\end{array}$ & 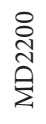 & $\stackrel{\vec{z}}{\vec{z}}$ \\
\hline
\end{tabular}


Table 2. Mean numbers ( \pm SE) of female and male P. papatasi

adults captured on eleven commercial traps $(n=11)$.

\begin{tabular}{llll}
\hline \multicolumn{1}{c}{ Trap } & \multicolumn{1}{c}{ Females $^{1}$} & \multicolumn{1}{c}{ Trap } & \multicolumn{1}{c}{ Males } \\
\hline SV35 & $212.6 \pm 34.2 \mathrm{a}$ & SV35 & $150.5 \pm 12.3 \mathrm{a}$ \\
SV27 & $141.2 \pm 13.8 \mathrm{~b}$ & SV27 & $120.9 \pm 12.3 \mathrm{a}$ \\
MMLIB+ & $139.3 \pm 14.0 \mathrm{~b}$ & MMPro & $67.7 \pm 13.6 \mathrm{~b}$ \\
MMPro & $134.9 \pm 17.2 \mathrm{~b}$ & MMLIB+ & $48.6 \pm 8.7 \mathrm{bc}$ \\
MMLib & $105.5 \pm 8.7 \mathrm{~b}$ & MMLib & $29.2 \pm 8.8 \mathrm{c}$ \\
MMDef & $95.2 \pm 14.1 \mathrm{~b}$ & MD2500 & $27.9 \pm 10.0 \mathrm{c}$ \\
MD2500 & $53.3 \pm 13.5 \mathrm{c}$ & MMDef & $24.7 \pm 7.3 \mathrm{~cd}$ \\
MPT & $34.7 \pm 8.7 \mathrm{~cd}$ & MK12 & $8.9 \pm 2.3 \mathrm{de}$ \\
MK01 & $32.2 \pm 5.3 \mathrm{~cd}$ & MK01 & $5.8 \pm 1.6 \mathrm{e}$ \\
MD2200 & $25.6 \pm 4.9 \mathrm{~cd}$ & MD2200 & $3.4 \pm 1.2 \mathrm{e}$ \\
MK12 & $19.2 \pm 6.5 \mathrm{~d}$ & MPT & $2.7 \pm 0.8 \mathrm{e}$ \\
\hline
\end{tabular}

SV27=Blue Rhino SV27, SV35=Blue Rhino SV35, MD2200=Coleman MD 2200, MD2500=Coleman MD 2500, MK12=Lentek Guardian MK 12, MK01=Lentek MK 01, MMDef=MM Defender, MMLib=MM Liberty, MMLIB+=MM Liberty plus, MMPro=MM-Pro, MPT=Mosquito Power Trap. ${ }^{1}$ Means in columns followed by the same letter are not significantly different $(\mathrm{P}<0.05$; Ryan-EinotGabriel-Welsch Multiple Range Test [SAS Institute 2003]).

females than any of the remaining traps (Table 2). Mean numbers of females captured by the Blue Rhino SV 27, the MM Liberty Plus, the MM Pro, the MM Liberty and the MM Defender were not significantly different, but were significantly greater than those captured by the Coleman MD 2500, the Mosquito Power Trap, the Lentek MK 01, the Coleman MD 2200. The mean number of females captured by the Lentek Guardian MK 12 was numerically less than the other 10 traps in the study (Table 1).

\section{Males}

Means for males captured ranged from 150.5 to 2.73 (Table 2). The Blue Rhino SV 35 and the Blue Rhino SV 2735 captured significantly more males than any of the remaining traps (Table 2). The mean numbers of males captured by the MM Pro and the MM Liberty Plus were not significantly different, however four overlapping significance levels separated the MM Liberty Plus and the Mosquito Power Trap, which had the smallest numerical catch.

\section{Trap catches by sex}

There were no significant differences between catches of females and males in only four of the eleven traps evaluated (Table 3). The SV-35 and SV-27, which were included among these four traps, were also the two traps that captured numerically more sand flies than the nine other traps.

\section{Position and day}

There were no significant differences between the mean numbers of females or males captured at any of the eleven trap positions. However, significant differences existed between mean numbers of females captured on different trap days. There were no significant differences for males. Plots of means for both sexes over time demonstrated the sinusoidal activity of the flies in the trapping area, with activity peaks at days 2, 6, and 9 (Figure 1).

\section{DISCUSSION}

Historically, three surveillance techniques have been used to collect adult phlebotomine sand flies: human landing collections, sticky papers and CDC light traps (KillickKendrick 1987, Hanafi et al. 2007). Although human landing collections often produce the largest numbers of sand flies (Hanafi et al. 2007), collections can also be highly variable and collectors are exposed to an increased risk of Leishmania infections. Therefore, CDC light traps (either with or without $\mathrm{CO}_{2}$ ) and sticky papers (with or without lights) have become the standard surveillance techniques.

Our data indicate that several propane combustionbased traps might also be suitable for adult sand fly surveillance. This is supported by a study in the Northern Sinai Desert of Egypt where MM-Pro traps caught $>10 \mathrm{X}$ more sand flies than dry ice baited CDC traps (D. Szumlas, personal communication). This is also supported by a study conducted on a military encampment in Iraq where 50 Mosquito Magnet traps (model not specified) were used to successfully reduce sand fly populations. This resulted in a $75 \%$ reduction in complaints (Blow et al. 2007). Hoel et al. (2010) compared mosquito traps powered with butane, a more common fuel in the Middle East, with CDC light traps baited with dry ice and found no significant differences between the mean numbers of sand flies captured. 


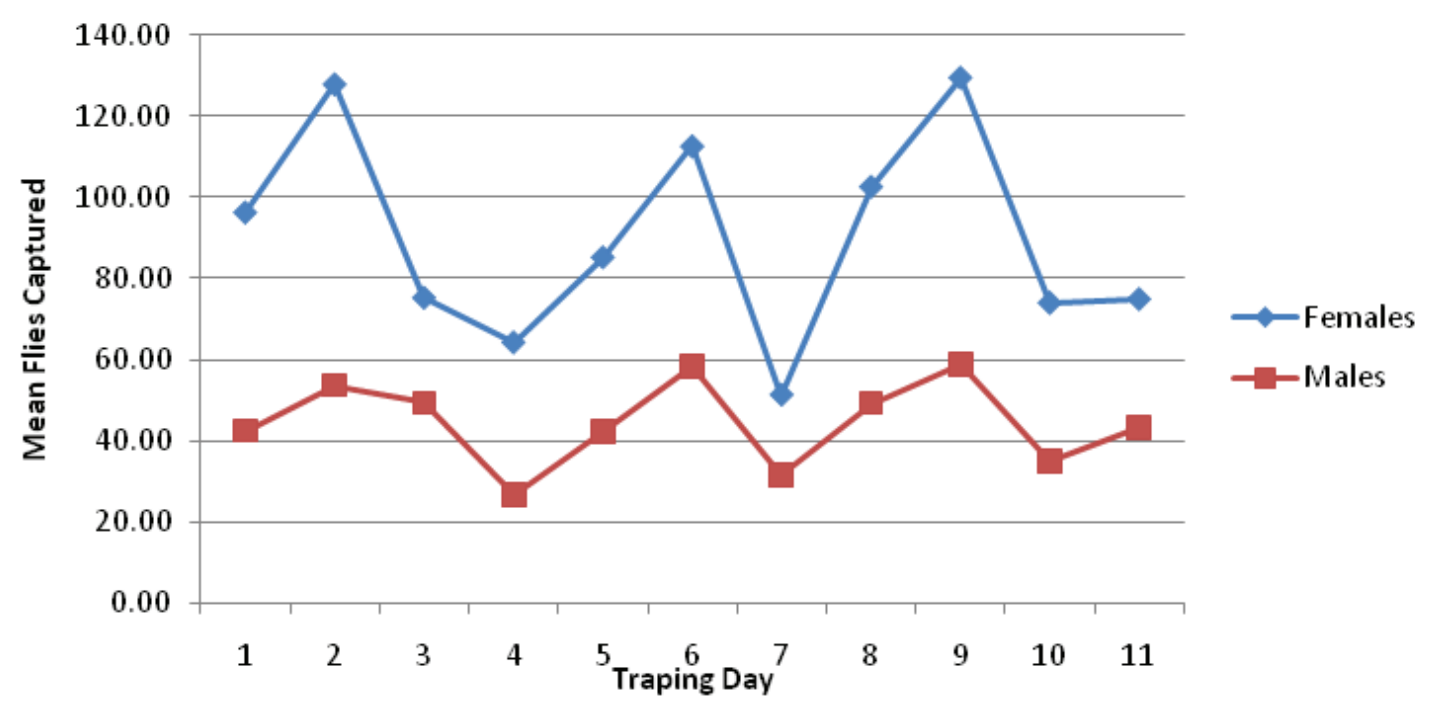

Figure 1. Mean numbers of $P$. papatasi females and males captured daily during the 11-day study.

Table 3. Differences in mean numbers $( \pm \mathrm{SE})$ of female and male P. papatasi adults captured on each of eleven commercial traps $(n=11)$.

\begin{tabular}{l|l|l}
\hline \multicolumn{1}{c|}{ Trap } & \multicolumn{1}{|c}{ Females $^{1}$} & \multicolumn{1}{c}{ Males } \\
\hline SV35 & $212.6 \pm 34.2^{*}$ & $150.5 \pm 12.3^{*}$ \\
SV27 & $141.2 \pm 13.8^{*}$ & $120.9 \pm 12.3^{*}$ \\
MMLIB+ & $139.3 \pm 14.0$ & $48.6 \pm 8.7$ \\
MMPro & $134.9 \pm 17.2$ & $67.7 \pm 13.6$ \\
MMLib & $105.5 \pm 8.7$ & $29.2 \pm 8.8$ \\
MMDef & $95.2 \pm 14.1$ & $24.7 \pm 7.3$ \\
MD2500 & $53.3 \pm 13.5^{\star}$ & $27.9 \pm 10.0^{\star}$ \\
MPT & $34.7 \pm 8.7$ & $2.7 \pm 0.8$ \\
MK01 & $32.2 \pm 5.3$ & $5.8 \pm 1.6$ \\
MD2200 & $25.6 \pm 4.9$ & $3.4 \pm 1.2$ \\
MK12 & $19.2 \pm 6.5^{\star}$ & $8.9 \pm 2.3^{\star}$ \\
\hline
\end{tabular}

SV27=Blue Rhino SV27, SV35=Blue Rhino SV35, MD2200=Coleman MD 2200, MD2500=Coleman MD 2500, MK12=Lentek Guardian MK 12, MK01=Lentek MK 01, MMDef=MM Defender, MMLib=MM Liberty, MMLIB+=MM Liberty plus, MMPro=MM-Pro, MPT $=$ Mosquito Power Trap.

${ }^{1}$ Means in rows followed by * are not significantly different $(\mathrm{P}<0.05$; Ryan-Einot-Gabriel-Welsch Multiple Range Test [SAS Institute 2003]).
Plotting daily mean numbers of sand flies captured during the eleven consecutive trapping days of our study produced a line for each sex that describes short-term fluctuations in population numbers (Figure 1). We have not found similar results in the literature and assume that this is the first time such periodicity has been reported. Further studies are needed to determine the significance of this phenomenon.

Several traps evaluated in our study, certainly the SV35 and SV-27, are definitely candidates for use in sand fly surveillance programs. Although we did not compare these traps directly with the CDC light trap, the MM Pro used in our study caught fewer sand flies than both SV models but compared favorably with the CDC trap. The SV models should be evaluated against sand fly species other than $P$. papatasi and under other environmental conditions to more fully determine their capabilities. Differences in trap design, notably the location and orientation of capture mechanisms, have been reported in sand fly studies (Mutero et al. 1991, Burkett et al. 2007). These and other attraction factors, such as lights and trap colors, should be further evaluated in an effort to improve the current selection of efficacious sand fly traps.

\section{Acknowledgments}

This study was supported in part by funds provided to the U.S. Department of Agriculture from the Department of Defense through the Deployed War-Fighter Protection Program (DWFP). We also thank Amy Junilla for suggestions for earlier versions of this manuscript.

\section{REFERENCES CITED}

Adler, S. and O. Theodor. 1957. Transmission of disease agents by phlebotomine sand flies. Annu. Rev. Entomol. 2: 203-226.

Alexander, B. 2000. Sampling methods for phlebotomine 
sand flies. Med. Vet. Entomol. 14: 109-122.

Al-Jawabreh, A., L.F. Schnur, A. Nasereddin, J.M. Schwenkenbecker, Z. Abdeen, F. Barghuthys, I.I. Khanfar, W. Presber, and G. Schonian. 2004. The recent emergence of Leishmania tropica in Jericho (A'riha) and its environs, a classical focus of L. major. Trop. Med. Int. Hlth. 9: 812-826.

Ashbel, D. 1951. Bio-climatic atlas of Israel. Meteorology Dept. of the Hebrew Univerity, Jerusalem. 151 pp. (Hebrew and English).

Ashford, R.W. 2001. Phlebotomus fevers. In: The encyclopedia of Arthropod-Transmitted Infections. M.W. Service (ed.). pp. 397-401. CABI Publishing, Wallingford, U.K.

Beavers, G.M., H.A. Hanafi, and E.A. Dykstra. 2004. Evaluation of 1-octen-3-ol and carbon dioxide as attractants for Phlebotomus papatasi (Diptera: Psyhodidae) in southern Egypt. J. Am. Mosq. Contr. Assoc. 20: 130-133.

Birtles, R.J. 2001. Carrion's disease. In: The encyclopedia of arthropod-transmitted infections. M.W. Service (ed.), pp. 104-106. CABI Publishing, Wallingford, U.K.

Blow, J.A., D.A. Forest, L.S. Long, J.J. Meckel, C.B. Raymond, and Carder, M.C. 2007. Challenges of effective vector control: Operation Iraqi Freedom 05-07. U.S. Army Med. Dept. J. (April-June): 46-53.

Burkett, D.A., R. Knight, J.A. Dennett, V. Sherwood, E. Rowton, and R.E. Coleman. 2007. Impact of phlebotomine sand flies on U.S. military operations at Tallil Air base, Iraq: 3. Evaluation of surveillance devices for the collection of adult sand flies. J. Med. Entomol. 44: 381-384.

Cilek, J.E. and C.F. Hallmon. 2005. The effectiveness of the Mosquito Magnet trap for reducing biting midge (Diptera: Ceratopogonidae) populations in coastal residential backyards. J. Am. Mosq. Contr. Assoc. 21: 218-221.

Cilek, J.E., D.L. Kline, and C.F. Hallmon. 2003. Evaluation of a novel removal trap system to reduce biting midge (Diptera: Ceratopogonidae) populations in Florida backyards. J. Vector Ecol. 28: 23-30.

Comer, J.A. and R.B.Tesh. 1991. Phlebotomine sand flies as vectors of vesiculoviruses: a review. Parasitologia 33: 143-150.

Danin, A. 1988. Flora and vegetation of Israel and adjacent areas. In: Yom-Tov and Tchernov (eds.). The Zoogeography of Israel. pp. 251-276. Junk Publishers, Dordrecht, Netherlands,

Faimen, R., R. Cuno, and A. Warburg. 2009. Comparative efficacy of three suction traps for collecting phlebotomine sand flies (Diptera: Pyschodidae) in open habitats. J. Vector Ecol. 34: 114-118.

Hanafi, H.A., D.J. Fryauff, G.B.Modi, M.O. Ibrahim, and A.J. Main. 2007. Bionomics of phlebotomine sandflies at a peacekeeping duty site in the north of Sinai, Egypt. Acta Trop. 101: 106-114.
Hoel, D.F., D.L. Kline, J.A. Hogsette, U.R. Bernier, S.S. ElHossary, H.A. Hanafi, N. Watany, E.Y. Fawaz, B.D. Furman, P.J. Obenauer, and D.E. Szumlas. 2010. Response of phlebotomine sand flies to light-emitting diode-modified light traps in southern Egypt. J. Med. Entomol. 47: 1179-1184.

Jaffe, C.L., G. Baneth, Z.A. Abdeen, Y. Schlein, and A. Warburg. 2004. Leishmaniasis in Israel and the Palestian Authority. Trends Parasitol. 20: 328-332.

Janini, R., E. Saliba, S. Khouri, O. Oumeish, S. Adwan and S. Kamhawi. 1995. Incrimination of Phlebotomus papatasi as vector of Leishmania major in the Southern Jordan Valley. Med. Vet. Entomol. 9: 420-422.

Killick-Kendrick, R. 1987. Methods for the study of phlebotomine sand flies. In: W. Peters and R. KillickKendrick. (eds.), The Leishmaniases in Biology and Medicine, vol. 1. pp. 473-497. Academic Press, London.

Margalit, J., M. Avrahami, and A.S. Tahori. 1973. Mosquitoes (Diptera: Culicidae) breeding in the Dead Sea Area. Israel J. Zool. 22: 27-37.

Muller, G. and Y. Schlein. 2004. Nectar and honeydew feeding of Phlebotomus papatasi in a focus of Leishmania major in Neot Hakikar oasis. J. Vector Ecol. 29: 154-158.

Mutero, C.M., M.J. Mutinga, M.H. Birley, F.A. Amimo and D.M. Munyinyi. 1991. Description and performance of an updraft trap for sandflies. Ann. Trop. Med. Parasit. 42: 407-412.

Orni, E. and E. Efrat. 1980. Geography of Israel. 4th ed. Israel University Press, Jerusalem, 556 pp.

SAS Institute. 2003. SAS/STAT User's Guide. Version 9.1, Cary, NC: SAS Institute.

Schlein, Y., A. Warburg., L.F. Schnur, S.M. Le Blancq, and A.E. Gunders. 1982. Leishmaniasis in the Jordan Valley II. Sand flies and transmission in the central endemic area. Trans. R. Soc. Trop. Med. Hyg. 76: 582-586.

Schlein, Y., A. Warburg, L. F. Schnur, S.M. Le Blancq, and A.E. Gunders. 1984. Leishmaniasis in Israel: reservoir hosts, sandfly vectors and leishmaial strains in the Negev, Central Arava and along the Dead Sea. Trans. R. Soc. Trop. Med. Hyg. 78: 480-484.

Wasserburg, G., Z. Abramsky, B.P. Kotler, R.S. Ostfeld, I.Yarom, and A.Warburg. 2003a. Anthropogenic disturbances enhance occurrence of cutaneous leishmaniasis in Israel deserts. Ecolog. Appl. 13: 868881.

Wasserburg, G., I. Yarom and A. Warburg. 2003b. Seasonal abundance patterns of the sandfly Phlebotomus papatasi in climatically distinct foci of cutaneous leishmaniasis in Israeli deserts. Med. Vet. Entomol. 17: 452-456.

Zohari, M. and G. Orshansky. 1949. Structure and ecology of the vegetation in the Dead Sea region of Palestine. Palest. J. Bot. 4: 177-206.

Zohari, M. 1982. Vegetal Landscapes of Israel. Am Oved, Tel Aviv. 336 pp. (In Hebrew). 